\title{
SALVOS PERO NO SANTOS: LA INCIDENCIA DE LA PROTESTANTIZACIÓN DEL ADVENTISMO EN LA PREPARACIÓN DE LOS CANDIDATOS AL BAUTISMO
}

Mg. EdgARdo D. IUORNO, PHD (C) Asociación Argentina Central Argentina 


\title{
Resumen
}

Salvos pero no santos: La incidencia de la protestantización del adventismo en la preparación de los candidatos al bautismo. Desde hace más de setenta años el adventismo ha sufrido un proceso de protestantización que a su vez ha suscitado cambios en la obra evangélica y la adoración. La visión hermenéutica original persiste, aunque debilitada, hay otra visión hermenéutica en competencia que gana terreno y afecta la misión de la iglesia y es la principal causa del estancamiento en el crecimiento. Aunque la organización ha percibido el problema, no se avizoran todavía soluciones claras. Se torna imprescindible un regreso a las raíces hermenéuticas del adventismo que reconfigure el enfoque evangelizador.

Palabras clave: Visión hermenéutica, evangelización pública, cambios de énfasis teológico, misión, contenido doctrinal.

\begin{abstract}
Saved but not Saints: The Incidence of Protestantization of the Adventism in the Preparation of the Candidates for Baptism. For more than seventy years, Adventism has undergone a process of protestantization which has brought changes in evangelical labor and worship. The original hermeneutical view persists, though weakened, there is another competing hermeneutical view that is gaining ground and affects the mission of the church and is the main cause of growth stagnation. Although the organization has perceived the problem, clear solutions are not yet in sight. A return to the hermeneutical roots of Adventism is essential to reconfigure the evangelistic focus.
\end{abstract}

Keywords: Hermeneutical view, public evangelization, changes of theological emphasis, mission, doctrinal content.

Recibido: 10/10/2021

Aceptado: 29/10/2021 
Estrategias para el Cumplimiento de la Misión 19, no. 1 (2021): 21-43

\title{
SALVOS PERO NO SANTOS: LA INCIDENCIA DE LA PROTESTANTIZACIÓN DEL ADVENTISMO EN LA PREPARACIÓN DE LOS CANDIDATOS AL BAUTISMO
}

\author{
MG. EdGARdo D. IUORNo, PHD (C) \\ Asociación Argentina Central \\ Argentina
}

\begin{abstract}
1. Introducción
Los adventistas del séptimo día son una denominación minoritaria, ${ }^{1}$ de 21 723992 miembros en el mundo, ${ }^{2}$ por lo cual se han acostumbrado a sacar el mayor provecho posible de los esfuerzos humanos y monetarios que realizan en procura de su objetivo. ${ }^{3}$ Procuran que se vean los frutos de sus esfuerzos, básicamente representados por la adhesión de nuevos miembros a su iglesia por medio del bautismo. ${ }^{4} \mathrm{El} \mathrm{hecho} \mathrm{de} \mathrm{crecer} \mathrm{en} \mathrm{número} \mathrm{les} \mathrm{per-}$ mite crecer en cantidad de nuevas iglesias y así ampliar la base de colaboradores y recursos para su vasta misión.

Dada la importancia que se le da en el adventismo a la adhesión de nuevos miembros, el estancamiento que ha venido experimentando desde hace unos años representa una preocupación para sus dirigentes a nivel mundial
\end{abstract}

1 Susana Bianchi, Historia de las religiones en la Argentina: Las minorías religiosas (Buenos Aires: Editorial Sudamericana, 2004), 89.

2 Office of Archives, Statistics and Research, 2021 Annual Statistical Report, vol. 3 (Silver Spring, MD: Seventh-day Adventist Church, 2021), 20.

3 J. C. Pound, "Evangelism Without Money", Ministry Magazine, abril 1940, 14-15.

4 Salim Japas, “El bautismo, ¿un sacramento?”, Ministerio Adventista, mayo 1973.

https://doi.org/10.17162/recm.v19i1.1591 
y sudamericano. ${ }^{5}$ ¿Porqué la retención de miembros es cada vez más difícil? ¿Hay causas meramente sociales para este fenómeno, o en verdad son teológicas?

Dado que el problema pareciera estribar en la preparación de los candidatos al bautismo, este artículo procura encontrar respuestas y soluciones a este dilema.

\section{La protestantización del adventismo}

La presentación realizada en 1888 por A. T. Jones y E. J. Waggoner cambió la atención de los estudios adventistas de la profecía (escatología) a la justificación por la fe y la experiencia de salvación (soteriología). ${ }^{6}$ Unos treinta años después de Minneapolis, una nueva forma de entender y conectar todo el cuerpo de doctrinas cristianas comenzó a manifestarse en el adventismo por medio de W. Prescott, la principal autoridad adventista en doctrina y ex editor de la Review (1901-1909). Prescott pensó que el enfoque de la doctrina adventista resultaba en un sistema rígido y compartimentado que no integraba las creencias con la persona de Cristo. Para corregir este problema, en 1920 publicó una obra titulada La doctrina de Cristo. El propósito de Prescott en este libro de texto para estudiantes de teología no era "desarrollar un esquema sistemático de teología" sino enfatizar "el significado de la revelación de Cristo como una experiencia en la vida". ${ }^{7}$ Con el

5 En cuanto al número de nuevos miembros, entre el 2016 y el 2019, no ha habido un incremento significativo en comparación con años anteriores. Office of Archives, Statistics and Research, 2020 Annual Statistical Report, vol 2 (Silver Spring, MD: Seventhday Adventist Church, 2021), 9; Roberto Gullón Canedo, Id y predicad el evangelio: Historia y análisis de los comienzos y desarrollo de la feligresía adventista en Sudamérica: 18942011 (Libertador San Martín, Entre Ríos: edición del autor, 2012). Al estancamiento se añade además el problema de la institucionalización, cf. David Trim, "Statistical Report 2019: Mission Trends and Resources", https://executivecommittee.adventist.org/wp-content/uploads/2019/10/Trim-David-2019-Annual-Council-StatisticalReport.pdf.

6 Roy E. Graf, "Cambios en la articulación de la teología adventista: Del santuario a la justificación por la fe", TeoBíblica 3, no. 1-2 (2017): 197-217; Roy E. Graf, The Principle of Articulation in Adventist Theology: An Evaluation of Current Interpretations and Proposal (Berrien Springs, MI: Adventist Theological Society Publications, 2019).

7 W. W. Prescott, The Doctrine of Christ: A Series of Bible Studies for Use in Colleges and Seminaries (Takoma Park, MD: Review \& Herald, 1920), 3. Según Graf, “LeRoy E. Froom evaluó que este libro fue un puente entre 1888 y el énfasis renovado en la justificación por la fe a partir de la década de 1920". Graf, "Cambios en la articulación de la teología adventista", 204-205.

https://doi.org/10.17162/recm.v19i1.1591 
paso del tiempo, otros pensadores adventistas interpretaron las Escrituras y las doctrinas adventistas desde esta nueva perspectiva. ${ }^{8}$

Más allá del énfasis práctico explícito de Prescott, Arthur G. Daniells entendió que los pastores adventistas y los miembros de la iglesia necesitaban incorporar el mensaje y la experiencia de 1888. En ese sentido, y de acuerdo con Daniells, la justicia por la fe es "una verdad esencial y todo abarcante" ${ }^{\prime 9}$ que "arroja un torrente de luz sobre el gran problema de la redención en todas sus fases" ${ }^{10}$ Por lo tanto, para Daniells, la doctrina de la justificación por la fe permite ver "todo el esquema de verdades bíblicas y su interconexión" y "juega el mismo papel hermenéutico antes realizado por la doctrina del santuario y los pilares del adventismo. ${ }^{11}$ Entonces, desde 1888, dos visiones hermenéuticas han coexistido implícitamente en el adventismo. La incompatibilidad de estas dos visiones, sin embargo, no se hizo evidente hasta casi un siglo después a partir de la crisis provocada por las enseñanzas de Desmond Ford. ${ }^{12}$

\section{Cambios en la obra evangélica y la adoración}

La obra evangélica y la adoración se están volviendo posmodernos, ecuménicos, saliendo progresivamente de la Escritura y acercándose a la Iglesia Católica. Pero los adventistas bíblicos están siguiendo el mismo sendero, atraídos por una visión hermenéutica de énfasis evangélico. Lo más probable es que los adventistas copien libremente y sin crítica alguna el pensamiento teológico y prácticas ministeriales de fuentes evangélicas que se basan en ideas filosóficas no bíblicas que introducen en el pensamiento y la vida de la iglesia consecuencias prácticas incompatibles con el pensamiento

8 Fernando Canale, "The Eclipse of Scripture and the Protestantization of the Adventist Mind, Part 1: The Assumed Compatibility of Adventism with Evangelical Theology and Ministerial Practices", JATS 21, no. 1-2 (2010); Fernando Canale, "The Eclipse of Scripture and the Protestantization of the Adventist Mind, Part 2: From the Evangelical Gospel to Culture", JATS 22, no. 1 (2011).

9 Arthur G. Daniells, Christ Our Righteousness (Washington, DC: Review \& Herald, 1941), 70 .

$10 \quad$ Ibíd., 71.

11 Fernando Canale, "From Vision to System: Finishing the Task of Adventist Theology, Part I: Historical Review", JATS 15, no. 2 (2004): 13-14.

12 David Elí Contreras Galván, “Desmond Ford y el santuario: Un repaso histórico" (monografía para "Tópicos contemporáneos de la Teología", Universidad de Montemorelos, marzo de 2019). 
bíblico. ${ }^{13}$ Las consecuencias no deseadas de este curso de acción están transformando el adventismo en una denominación carismática genérica no bíblica y secular, de lo cual la evangelización es una muestra. Al parecer, la mayoría de los líderes y miembros de la Iglesia Adventista del Séptimo Día (IASD) no comprenden los supuestos y las consecuencias no intencionadas de los cambios promovidos en la práctica del ministerio. El hecho de que existan algunos predicadores con cierta tendencia y éxito, revela que la visión evangélica es la dominante en la actualidad. ${ }^{14}$

Para Fernando Canale, la situación que enfrentamos en el ministerio y la liturgia de la iglesia involucra la protestantización de la mente adventista y el eclipse de las Escrituras. ${ }^{15}$ Para superar estos desafíos dentro del adventismo, debemos alcanzar la mente posmoderna y mantener a los jóvenes en la iglesia con una evaluación crítica de nuestra propia experiencia, una comprensión sistemática de las verdades bíblicas y la aplicación de paradigmas bíblicos en lo ministerial y litúrgico. ${ }^{16}$

El adventismo ha estado experimentando a principios del siglo XXI un cambio macro a nivel de base: la cultura está eclipsando las Escrituras. Este fenómeno consiste en el bloqueo y oscurecimiento del papel y la comprensión de los contenidos de las Escrituras en la vida, adoración, espiritualidad, pensamiento y actuación de los creyentes adventistas. El eclipse de las Escrituras es siempre parcial. Comienza con la negligencia del estudio de la Biblia y procede a bloquear la comprensión de las Escrituras por el abrazo de diferentes formas culturales de pensar e interpretar las Escrituras. El eclipse de las Escrituras acompaña el proceso de protestantización de la mente adventista que resulta de la suposición generalizada de que la teología evangélica es correcta en toda doctrina cristiana, excepto en los distintivos adventistas.

Durante más de un siglo, los adventistas entendieron que Dios les dio una misión (la condición teleológica del método teológico) que incluía no solo al mundo no cristiano en general, sino también los creyentes cristianos en el mundo católico romano. ${ }^{17}$ La predicación del evangelio a todo el

13 Fernando Canale, Adventismo Secular? Como entender la relación entre estilo de vida y salvacion (Ñaña, Lima: Universidad Peruana Unión, 2012), 58.

14 Rubens Lessa, "Pastor Bullón explica Projeto Sol”, Revista Adventista, abril 1988.

15 Alberto R. Timm, “Antecedentes históricos de la interpretación adventista de la Biblia", en Entender las Sagradas Escrituras (Florida: Asociación Casa Editora Sudamericana, 2006), 17. Este proceso ya afectó a otras denominaciones.

16

Canale, "The Eclipse of Scripture and the Protestantization, Part 1", 135.

17 Daniel Hammerly, “A Better Approach to Roman Catholics”, Ministry Magazine, agosto $1947,5,6$. 
mundo en el contexto de las profecías del tiempo del fin dadas en Daniel y Apocalipsis implica el ayudar a otros cristianos a moverse de una comprensión basada en la tradición del cristianismo a una base bíblica. ${ }^{18}$

Sin embargo, a fines del siglo XIX, un cambio de paradigma en la metodología teológica adventista ya había comenzado. A causa del énfasis en el logro concreto de la condición teleológica de la teología adventista (la misión de la iglesia al mundo), la iglesia pasó involuntariamente de una mentalidad teológica a una práctica. Esto provocó un decaimiento progresivo en el interés por la compresión teológica del texto bíblico, haciéndola así menos importante. Entonces, los adventistas pronto abandonaron el primer paso metodológico, leer materiales teológicos. Entonces, se fue diluyendo la convicción de que Babilonia es "la madre de las rameras" (Ap 17:5) cuyas hijas se aferran a sus doctrinas y tradiciones siguiendo el ejemplo de la madre al sacrificar la verdad y la aprobación de Dios, para formar un acto ilegal de alianza con el mundo.19 "El mensaje de Apocalipsis 14, que anuncia la caída de Babilonia, debe aplicarse a comunidades religiosas que un tiempo fueron puras y luego se han corrompido".$^{20}$ Inclusive, es a partir del entendimiento de Apocalipsis 14 que nace el imperativo de dar la advertencia a la humanidad en los últimos días. Por lo tanto, hablar de Babilonia no puede referirse solo a la Iglesia Católica, porque esa iglesia ha estado en una condición caída por muchos siglos, sino también a los cuerpos religiosos que siguen el mismo camino. Más aún, en el capítulo dieciocho de Apocalipsis, Dios llama a su pueblo a salir de Babilonia. De este modo no se puede confiar en los teólogos evangélicos simplemente porque afirman que basan sus doctrinas en la Escritura. ${ }^{21}$

Podemos rastrear los inicios de este cambio de paradigma en teología y metodología, por ejemplo, en las opiniones de Waggoner y Jones sobre justificación, santificación y perfección. Waggoner y Jones tomaron prestada la teología de John Wesley ignorando que este se basaba en enseñanzas ontológicas católico romanas, propagando así una perfección de tipo wesleyano que desemboca en el movimiento de santidad. Esto explica porque el evangelicalismo conservador ha sido durante mucho tiempo el punto de

18 Daniel Belvedere, "El ABC del Seminario Revelaciones del Apocalipsis", Ministerio Adventista, marzo 1988.

19 Larry Christoffel, "Evangelical Adventism-Questions on Doctrine's Legacy", 2007, disponible en https://digitalcommons.andrews.edu/cgi/viewcontent.cgi?article $=1009 \&$ context $=$ qod.

20 Ellen G. White, El conflicto de los siglos (Doral, FL: Asociación Publicadora Interamericana, 2007), 380.

21 Ibíd. 
referencia principal para el adventismo. De este modo, según Canale, la protestantización del adventismo ha moldeado el pensamiento, la espiritualidad y la misión de la iglesia durante más de un siglo. En tal caso, Questions on Doctrines $(Q O D)$ y Glacier View es solo un elemento emergente de esta asimilación.22

\section{Los cambios que sucitó el libro Questions on Doctrine}

La suposición detrás de los logros académicos del fundamentalismo adventista era que, si un tema fuera examinado a fondo, la posición adventista sería vindicada. Fue esta suposición la que subyació al diálogo con los evangélicos que originó el libro QOD.23 Pero fue aquí donde la iglesia finalmente se extralimitó, porque esta obra levantó incertidumbres sobre lo que los adventistas realmente creían e hizo de la era evangélica que siguió fuera la más desestabilizadora en la historia de la iglesia. ${ }^{24}$

Los autores de $Q O D$ habían experimentado, probablemente en diferentes formas y en diferentes grados, el cambio a nivel macro en la metodolo-

22 Denis Fortin, "Questions on Doctrine and the Church: Where Do We Go from Here?" (Questions on Doctrine 50th Anniversary Conference, Berrien Springs, MI, 2007); General Conference of Seventh Day Adventists, Seventh-Day Adventists Answer Questions on Doctrine: An Explanation of Certain Major Aspects of Seventh-Day Adventist Belief (Washington, DC: Review \& Herald, 1957); George R. Knight, “Questions on Doctrine: Symbol of Adventist Theological Tension" (Questions on Doctrine 50th Anniversary Conference, Berrien Springs, MI, 2007); Juhyeok Nam, "Reactions to the Seventh-Day Adventist Evangelical Conferences and Questions on Doctrine, 1955-1971", resumen, AUSS 43, no. 2 (2005): 333; Arthur Patrick, "The Questions on Doctrine Event: Contrasting Perceptions, Their Impact and Potential" (Questions on Doctrine 50th Anniversary Conference, Berrien Springs, MI, 2007); Alberto R. Timm, “Questions on Doctrine: History and Impact in the South American Division" (Questions on Doctrine 50th Anniversary Conference, Berrien Springs, MI, 2007); Desmond Ford, "Des Ford Reflects on His Adventist History", Spectrum, 12 de marzo, 2015, disponible en https://spectrummagazine.org/article/2015/03/12/des-ford-reflects-his-adventist-history; Glauber Araujo, “Desmond Ford e a doutrina do santuário: Análise comparativa de duas fases distintas" (Tesis de licenciatura, Universidad Adventista de São Paulo, 2006).

23 Roy Allan Anderson, "Seventh-day Adventists Answer Questions on Doctrine", Ministry Magazine, junio 1957, 24.

24 Julius Nam, "Questions on Doctrine and M. L. Andreasen: The Behind-the-scenes Interactions", AUSS 46, no. 2 (2008): 229-244; M. L. Andreasen, Letters to the Churches (Brushton, NY: Teach Services, 1996).

https://doi.org/10.17162/recm.v19i1.1591 
gía teológica descrito arriba. Mientras los adventistas comunicaban las Escrituras sin buscar la comprensión de su contenido teológico y espiritual, fueron perdieron la visión hermenéutica que los primeros pioneros y Ellen G. White habían encontrado en la doctrina del santuario.

Contrariamente a las percepciones de muchos lectores, los contenidos de $Q O D$ no entregaron el adventismo a la teología evangélica. Sin embargo, Canale advierte que la respuesta a la primera pregunta de $Q O D$, ¿qué doctrinas comparten los adventistas con otros cristianos?, evidencia rastros de la protestantización de la mente adventista. Los autores de $Q O D$ respondieron que, con la excepción de algunos puntos doctrinales, tales como la existencia del santuario, el juicio investigador, el espíritu de profecía, los tres mensajes angélicos, el sello de Dios y la marca de la bestia; son mayores los acuerdos que las diferencias, lo cual fue aplaudido por algunos evangélicos. ${ }^{25}$

LeRoy E. Froom fue el primero en reconocer e interpretar los cambios teológicos que habían tenido lugar dentro del adventismo. Según Froom, la IASD había sido conducida gradualmente hacia una comprensión completa del evangelio cristiano después de un siglo en el que las verdades importantes como el sábado, se habían equilibrado con la comprensión correcta de la doctrina de Cristo y su obra salvadora. Así, se presentan tres categorías de doctrinas: las que los adventistas comparten con todos los cristianos, las que sostienen con algunos y las individuales. Más tarde, Froom, intentó superar ese reduccionismo en el capítulo "Sanctuary Truth Pivotal Teaching of Adventism" de su libro Movement of Destiny publicado el año $1971 .{ }^{26}$

La respuesta de Froom enumerando superficialmente similitudes en cuestiones doctrinales no aborda las verdaderas posiciones teológicas divergentes, ni los sistemas y métodos teológicos adoptados por adventistas y protestantes. El primer paso en la protestantización del adventismo ya estaba dado en las mentes de los líderes adventistas. A partir de ello, fue posible una protestantización mucho más acelerada. Se reconoce entonces a Froom como el pensador fundamental en el nuevo evangelicalismo adventista. Aunque Froom no sugirió que los adventistas deberían abandonar su doctrina del santuario, buscó suavizar su efecto divisor ignorando su

25 The Ministerial Association, Doctrinal Discussions: A Compilation of Articles Originally Appearing in The Ministry, June, 1960 - July, 1961, in Answer to Walter R. Martin's Book The Truth About Seventh-day Adventism (Washington, DC: Review \& Herald, 1961); Walter R. Martin, Donald Grey Barnhouse y H. W. Lowe, The Truth about Seventh-day Adventism (Grand Rapids: Zondervan, 1960).

26 LeRoy Edwin Froom, Movement of Destiny (Washington, DC: Review \& Herald, 1971), 541-560. 
papel hermenéutico; así, afirmó la doctrina, pero redefinió su función. Siguiendo el ejemplo de $Q O D$, la sutil redefinición del santuario por parte de Froom en la que el rol de esta doctrina pasaba de ser la clave hermenéutica para ser una doctrina distintiva, tuvo consecuencias de largo alcance en el método teológico, sistema y enseñanzas teológicas, y la praxis ministerial. De ahí, la progresiva protestantización del adventismo se construye y nutre. Aunque $Q O D$ dejó intacta la doctrina del santuario, comenzó a erosionar sus cimientos. Lo que pretendía ser simplemente un cambio cosmético terminó perturbando el equilibrio de todo el sistema teológico adventista.

¿Cuál fue entonces la nueva clave hermenéutica implícita en el adventismo después de QOD? Froom asumió implícitamente el evangelio como el nuevo principio hermenéutico en el adventismo. Aunque la doctrina del santuario siguió siendo un importante distintivo escatológico, los líderes ya no la concibieron ni utilizaron como la clave hermenéutica para comprender todas las doctrinas cristianas, incluido el evangelio. Al menos después de $Q O D$, el evangelio se entendió como lo entiende la teología evangélica. La tradición se convirtió por defecto en la clave hermenéutica implícita para interpretar todas las doctrinas que incluyen escatología y el santuario. Este cambio en la comprensión de las condiciones hermenéuticas de la metodología teológica requiere un cambio en la condición del material. Ya que la teología evangélica no se basa solo en las Escrituras, progresivamente los adventistas ya no desarrollarían su comprensión teológica de la Escritura sola sino a partir de la multiplicidad de patrones.

Sin embargo, para su crédito, Froom y algunos adventistas bíblicos conservadores no se rindieron a la tradición evangélica por completo. No tomaron sus supuestos ontológicos de la tradición sino de la Escritura. Ellos entendieron correctamente la realidad del santuario desde una ontología bíblica. Esto significa que no espiritualizaron el santuario siguiendo el patrón de la atemporalidad platónica, sino que afirmaron la realidad espaciotemporal del santuario y ministerio de Cristo en el cielo. Froom no espiritualiza la realidad de los actos de Dios y el santuario celestial según la ontología atemporal de la tradición cristiana, sino que reafirma la ontología histórica bíblica. Esto revela una inconsistencia y tensión internas en la visión doctrinal de Froom porque la aplicación de la comprensión del evangelio como clave hermenéutica requiere el rechazo de la ontología bíblica y la adopción implícita o explícita de ontología de Platón interpretada por Agustín y Tomás de Aquino. Es decir, se quedó al borde de asumir una ontología platónica de Dios que reemplace implícita o explícitamente la ontología bíblica de Dios, lo cual llevará a la protestantización completa del adventismo y lo tornará modernista y ecuménico.

Este cambio de paradigma representa un cambio radical desde la experiencia de los primeros pioneros adventistas quienes, insatisfechos con las 
teologías protestantes tradicionales, decidieron seguir su propia comprensión de la verdad bíblica, abandonando sus denominaciones evangélicas para convertirse en la iglesia remanente. Así, la “adopción de un nuevo principio articulador de la teología adventista también permite comprender por qué los adventistas tienen algunas dificultades para ver la diferencia esencial entre la teología adventista y otros sistemas teológicos protestantes o evangélicos" ${ }^{27}$

Aunque la protestantización del adventismo está cambiando las mentes y los corazones de los adventistas bíblicos de todo el mundo y sus esfuerzos evangelísticos, las formulaciones doctrinales permanecen conservadoras y reflejan tiempos anteriores cuando la doctrina del santuario fue la llave hermenéutica que se abrió para ver una sistema completo y armonioso de teología bíblica. No obstante, se aprecia una creciente disociación entre discurso teológico y práctica evangelizadora. ¿Será que la iglesia, aunque es adventista por fuera, ahora es evangélica por dentro?

Claramente, la protestantización del adventismo y el eclipse de las Escrituras son más difíciles de evaluar porque no son elementos externos sino internos y propios de la experiencia adventista. Además, los cambios y desafíos que producen no son cosméticos ni superficiales, sino que afectan profundamente la base, esencia y misión de la iglesia remanente. Sin embargo, la mayoría de los adventistas que promueven innovaciones y siguen de cerca las últimas tendencias evangélicas no son conscientes de que están cambiando la esencia y la naturaleza del adventismo. ${ }^{28}$ Además, la mayoría de líderes y miembros de la iglesia no comprenden los supuestos y las consecuencias no intencionadas de los cambios que van teniendo lugar en la práctica del ministerio.

En el diagrama que se presenta a continuación, Canale explica cómo el cambio de enfoque teológico relegó la evangelización extendida y doctrinaria reemplazándola por el "evangelio", la disoció del estilo de vida con su consecuente impacto en el incremento de la apostasía y la pérdida de solidez en la iglesia y el liderazgo que surgió de ella desde los 90 en adelante. ${ }^{29}$

27 Graf, "Cambios en la articulación de la teología adventista", 16.

28 Como ejemplo véase el siguiente video: https://www.youtube.com/watch?v=W_ aLaY5Kr4Y\&feature=youtu.be.

29 Canale, Adventismo Secular?, 108. 
Diferencias en los enfoques teológicos del adventismo

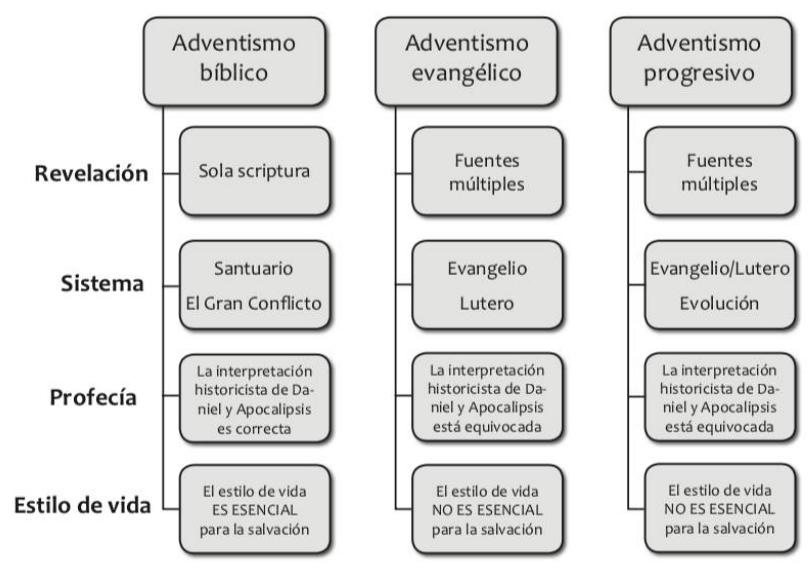

Por ejemplo, Arthur Patrick argumenta que Ellen G. White, cofundadora del adventismo y su autora más notable, fue claramente evangélica. ${ }^{30}$ Otros adventistas evangélicos consideran que las posiciones tomadas en $Q O D$ son una expresión del adventismo auténtico y evangélico. Por su parte, George Knight no solo cree que la teología evangélica es correcta y la adopta como adventista, sino que piensa que los adventistas encuentran el significado de lo que los hace tales en el marco de la teología evangélica. ${ }^{31}$ Aunque no lo perciba, esto es precisamente lo que ha llevado a la esterilización del adventismo que él describe y denuncia correctamente. ${ }^{32}$ Hoy en día, cuando se refiere a la hermenéutica teológica adventista, los adventistas bíblicos ya no se refieren al santuario sino a la gran controversia, estrechamente relacionados pero no idénticos. ${ }^{33}$ Además, la doctrina del santuario proporciona el marco teológico interno para la interpretación teológica de la historia de la salvación tal como lo es la gran controversia.

30 Arthur Patrick, “Are Adventists Evangelical?”, Ministry Magazine, febrero 1995.

31 George R. Knight y Gilbert M. Valentine, Adventist Maverick: A Celebration of George R. Knight's Contribution to Adventist Thought (Nampa, ID: Pacific Press, 2014), 140.

32 George R. Knight, The Apocalyptic Vision and the Neutering of Adventism (Review \& Herald, 2008).

33 Herbert E. Douglass, ed., The Heartbeat of Adventism: The Great Controversy Theme in the Writings of Ellen G. White (Nampa, ID: Pacific Press, 2010). 


\section{Dos visiones en competencia ante el desafío académico}

Canale recuerda que el adventismo de 1960 entró en una frontera inexplorada, la universidad. La matriz a partir de la cual se genera la reflexión teológica fue desplazada del ámbito práctico del ministerio, el evangelismo y la administración al ámbito técnico de la erudición. Cuando los adventistas ingresaron al mundo académico en el que las ciencias de diferentes tipos no solo se enseñan, sino que también se crean, se encontraron con nuevas preguntas fundamentales. No es sorprendente que estas preguntas desafiaran a los eruditos adventistas. Para contestarlas, necesitaban tener una concepción de principios inequívoca, coherente y sistemática claramente formulada. En términos simples, necesitaban una visión articulada de manera académica y una metodología teológica completa. Desafortunadamente, tal visión académica formulada no solo era inexistente, sino que además el adventismo estaba operando implícitamente con dos visiones en competencia: el santuario y la justificación por la fe. En consecuencia, los académicos adventistas se enfrentaron durante este período a la difícil tarea de superar las ambigüedades teológicas heredadas de períodos anteriores y afrontar nuevos desafíos presentados por el mundo académico sin una comprensión explícita de la visión hermenéutica o del camino en el que funciona el método teológico.

A medida que los adventistas participaban en estudios de posgrado e investigación académica, se enfocaron sobre cuestiones cronológicas, arqueológicas, históricas y exegéticas. Esta concentración alejó la reflexión teológica de la naturaleza sistemática y dinámica del pensamiento adventista temprano. Por lo tanto, el papel de la visión hermenéutica en la investigación académica se hizo cada vez menos clara para las nuevas generaciones de eruditos adventistas y creyentes. Como se descuidó la interconexión del pensamiento, los creyentes adventistas comenzaron a experimentar las doctrinas de la iglesia como afirmaciones desconectadas, separadas de la experiencia de salvación y la misión de la iglesia, tal como se ve en estudios de Knight ${ }^{34}$ y Norman R. Gulley. ${ }^{35}$ Mientras tanto, la vida y acción del cuerpo de la iglesia se absorbieron en la práctica y la misión, en detrimento de la reflexión teológica. El énfasis en el lado práctico de la experiencia de la iglesia puso en marcha un proceso que, con el tiempo, produjo una

34 George R. Knight, “Adventist Theology: 1844 to 1994”, Ministry Magazine, agosto 1994.

35 Norman R. Gulley, “Christ-Centered Expression of Our Faith”, Ministry Magazine, marzo 1997, 24-27. 
desconexión entre pastores y maestros (Ef 4:11), entre la práctica y la teología - o la instalación de modelos basados en la visión hermenéutica evangélica. El impulso teológico que dirigió el curso futuro del adventismo fue disminuyendo lentamente y minimizando así la importancia de la visión hermenéutica y su papel en la generación del pensamiento teológico. ${ }^{36}$

La revisión histórica de la teología adventista hecha por Froom revela la ambigüedad existente en el pensamiento adventista durante los años sesenta y setenta. ${ }^{37}$ En The Prophetic Faith of Our Fathers y The Conditionalist Faith of Our Fathers, Froom pretende demostrar la herencia previa de los hitos adventistas. En el telón de fondo de $Q O D$, los adventistas diferenciaron verdades eternas de verdades de prueba, trasluciendo la convicción de que las creencias adventistas del séptimo día eran ya sostenidas por uno o más grupos cristianos, lo cual ha sido ampliamente aceptado en todos los sectores del adventismo. Por lo tanto, parece que hace casi sesenta años, algunos sectores del liderazgo adventista comenzaron a pensar que había muy poca diferencia entre los adventistas y las doctrinas evangélicas. Como consecuencia de este pensamiento, la IASD no sería la iglesia remanente sino una denominación evangélica más. Este cambio de convicción puede ayudarnos a comprender los cambios que tuvieron lugar en el adventismo en la segunda mitad del siglo los cuales se reflejaron en la evangelización pública.

Como los adventistas comenzaron a usar el énfasis soteriológico como visión hermenéutica desde la cual comprender las Escrituras y construir su sistema teológico, la visión hermenéutica del santuario fue reemplazada por la visión hermenéutica soteriológica propia del protestantismo clásico. Diez años después, Ford expresó este reemplazo explícita y teóricamente, desatando un cambio de paradigma en la hermenéutica y teología adventistas. El rechazo articulado, académico y carismático que Ford hizo de la doctrina del santuario atrajo la atención de toda la iglesia. Tal rechazo dio expresión explícita al cambio hermenéutico implícito hallando cabida en algunos sectores del adventismo.

36 Fernando Canale, "Vision and Mission-Part 1: Historical and Methodological Background", JATS 26, no. 2 (2015): 111-148.

37 LeRoy Edwin Froom, The Prophetic Faith of Our Fathers: The Historical Development of Prophetic Interpretation, vol. 4 (Washington, DC: Review \& Herald, 1948); LeRoy Edwin Froom, The Conditionalist Faith of Our Fathers, 2 vols. (Washington, DC: Review \& Herald, 1965). 


\section{Las etapas del desarrollo teológico adventista}

A medida que el evangelicalismo se volvió menos sectario, el adventismo del séptimo día comenzó a parecer más evangélico. Así, algunos investigadores como Walter R. Martin llegaron a la conclusión de que "los adventistas son un grupo verdaderamente cristiano". ${ }^{38}$

La teología general del adventismo se mantuvo cerca del evangelicalismo conservador, pero estaba separada de ella por las posiciones distintivas de la denominación. La respuesta adventista estándar a esto ha sido mostrar que incluso los puntos de vista inusuales del adventismo provienen de fuentes que los evangélicos afirman como propias. En sus enormes obras ya referidas, Froom trazó las raíces de la escatología adventista y la doctrina de la inmortalidad condicional del alma a través de los siglos. Los adventistas también han estado activos en la búsqueda de grupos guardadores del sábado perdidos en la historia, encontrando su propia posición anunciada por las antiguas iglesias de etíopes, armenios y celtas. ${ }^{39}$

Si bien es cierto que el adventismo del siglo XXI difiere del evangelicalismo contemporáneo en solo unas pocas creencias, tal comparación doctrina por doctrina no es del todo útil para establecer el carácter y la posición histórica de la teología adventista. Dentro del cristianismo, diversos grupos pueden compartir posiciones teológicas superficialmente similares por razones completamente fortuitas, y muchos de los estudios históricos de los adventistas han investigado paralelos en lugar de conexiones. Sin embargo, en los últimos años, a través de los estudios de los orígenes de la iglesia, ha surgido una imagen más clara de la posición histórica del adventismo. Las influencias más importantes en la formación de la teología adventista fueron el millerismo, los bautistas del séptimo día, la Conexión Cristiana y el metodismo. Asi, el millerismo fue el movimiento del que surgió el adventismo; los bautistas del séptimo día proveyeron parte de la doctrina definitoria del sábado; Joseph Bates y James White, los primeros líderes adventistas más importantes, fueron ministros en la Conexión Cristiana; y Ellen G. White fue metodista. ${ }^{40}$ ence of Seventh Day, 1999); Kenneth A. Strand, ed., Sabbath in Scripture and History (Washington, DC: E. P. Dutton, 1982).

40 Merlin D. Burt, "Making a Movement: The Linking of the Sabbath and Heavenly Sanctuary Ministry of Jesus in Early Adventist History" (Fourth International Bible 
En términos históricos, el adventismo del séptimo día fue eliminado en dos etapas de la corriente principal protestante. Por lo tanto, la identidad adventista no depende de unas pocas doctrinas que se desvían de las de la corriente protestante principal sino en una historia distinta que está aislada de dicha corriente. Los adventistas han surgido aparte y esto pone un límite natural a su capacidad de moverse desde los márgenes de la vida religiosa hacia el centro. ${ }^{41}$

Las interpretaciones adventistas de su propia historia teológica son ampliamente compatibles con este enfoque. Froom fue el primero en reconocer e interpretar los cambios teológicos que tuvieron lugar dentro del adventismo. Froom abogó por una especie de comprensión progresiva, aunque no fue el único. ${ }^{42}$ La iglesia había sido conducida gradualmente hacia una comprensión completa del evangelio cristiano después de un siglo en el que las verdades importantes como el sábado habían sido acompañadas por la interpretación errónea de la doctrina de Cristo y su obra salvadora. Froom argumentó que este proceso había logrado la alineación del adventismo con el cristianismo evangélico.

Otra perspectiva adventista ofrece una interpretación teológica diferente del mismo conjunto de datos. Los adventistas conservadores, como el ex presidente de la iglesia Robert Pierson, perciben los cambios que han tenido lugar dentro del adventismo como una disminución de la pureza prístina más que como una evidencia de la continua guía divina. Según esta escuela de pensamiento, el movimiento de secta a denominación ha implicado la dilución del mensaje adventista en deferencia a las expectativas de los académicos seculares. Todas estas interpretaciones están de acuerdo con los hechos básicos. En el siglo XIX, el adventismo estaba estrechamente vinculado a sus doctrinas peculiares, y en el siglo $\mathrm{XX}$, esos vínculos se relajaron a medida que el adventismo se volvió menos distintivo.

\section{Visión y misión}

Como se ha visto, cuando el santuario pasó de ser una visión hermenéutica fundacional a una doctrina distintiva se fue perdiendo la herramienta necesaria para discernir la diferencia entre herejía y verdad. Una desconexión

Conference, Roma: Biblical Research Institute, General Conference of Seventh-Day Adventists, 2018).

41 Alberto R. Timm, El santuario y los mensajes de los tres ángeles (Florida: Asociación Casa Editora Sudamericana, 2018).

42 Miguel Angel Nuñez, La verdad progresiva (Lima, Perú: Fortaleza Ediciones, 2007).

https://doi.org/10.17162/recm.v19i1.1591 
sistémica entre los aspectos administrativos, ministeriales, misioneros, educativos y médicos de la iglesia se dieron de manera progresiva hasta convertirse en el modus operandi del liderazgo adventista del séptimo día. ${ }^{43}$ Esta desconexión sistémica, exigida por la alta especialización y diversificación del conocimiento que tuvo lugar durante el siglo $X X$, ha intensificado y acelerado la inevitable consecuencia del abandono y olvido que las generaciones anteriores hicieron de la visión adventista.

Este escenario demuestra cuan necesario es repensar y reformular el evangelio a la luz de la visión adventista. La sociedad posmoderna anhela formas de dar sentido y sanar sus experiencias de lo causado por el relativismo y el materialismo. Además, está abierta a soluciones espirituales y narraciones amorosas. Esto parece indicar que Dios ha preparado al mundo para escuchar la narrativa histórica del evangelio y el gran conflicto descubierto por los adventistas hace 200 años. La misión no es otra cosa que compartir dicha visión hermenéutica.

\section{Del énfasis bíblico-doctrinal al énfasis bíblico-relacional}

Alberto R. Timm se preguntó si ante las fuertes corrientes de la globalización ecuménica la IASD no estaría en peligro de perder su identidad. ${ }^{44}$ En su búsqueda, encontró que el período de énfasis bíblico-doctrinal fue de 1844 a 1980. Los adventistas fueron conocidos, durante muchos años, como el pueblo de la Biblia. Timm sugiere que los fundadores del adventismo amaban realmente la verdad, y eran estudiosos profundos de la Palabra de Dios. ${ }^{45}$ William Miller, por ejemplo, comenzó un período de estudio secuencial de la Biblia en 1816, partiendo en Génesis 1:1 y continuando al siguiente versículo solo después de haber entendido satisfactoriamente el anterior.

Los pioneros del movimiento adventista mostraron amor a la Biblia mediante el conocimiento doctrinal de las Escrituras y la comprensión de los textos bíblicos. El mismo amor continuó siendo una de las marcas distintivas de los adventistas hasta finales de la década de 1970. Esto se reflejó tanto en el contenido de los sermones predicados como en los estudios bíblicos dados y en los programas juveniles.

43 Fernando Canale, Vision \& Mission: How a Theological Vision Drives the Mission of the Emerging Remnant (North Charleston, SC: CreateSpace, 2015).

44 Alberto R. Timm, “Hermenéutica Adventista del Séptimo Día, 1844-1999: Un breve panorama histórico", en Entender la Palabra: Hermenéutica adventista para el nuevo siglo, ed. Merling Alomía et al. (Cochabamba: Universidad Adventista de Bolivia, 2000).

45 Alberto R. Timm, "Podemos ainda ser considerados a povo da Biblia?", Revista Adventista, junio 2001, 14-16.

https://doi.org/10.17162/recm.v19i1.1591 
Los adventistas fueron respetados e incluso temidos por grupos evangélicos debido a su profundo conocimiento bíblico. Los adventistas incluso se jactaban de que una de las evidencias de tener la verdad era el hecho de que sus miembros, si algunos de ellos abandonaban la iglesia, no se unían a ninguna otra denominación.

A esto se suma que entre 1844 y 1980 era una costumbre adventista hacer el Año Bíblico. Algunos llegaron a leer la Biblia entera entre sesenta y cien veces. Esta misma dedicación a las Escrituras contribuyó a que varios adventistas ganaran concursos bíblicos nacionales e internacionales. ${ }^{46}$

Desde 1981, Timm entendió el inicio de un nuevo período, de énfasis bíblico-relacional. ${ }^{47} \mathrm{Si}$ hasta finales de la década de 1970, los adventistas se caracterizaron por su conocimiento bíblico-doctrinal, a partir de la década de 1980 esta característica comenzó a suplantarse lentamente por un nuevo énfasis bíblico-relacional. En otras palabras, el interés en el conocimiento racional de las enseñanzas bíblicas terminó siendo superado por una lectura existencialista de la Biblia, como una forma de nutrir la relación con la persona de Cristo.

Fundamental para esta transición fueron algunas obras del pastor estadounidense Morris L. Venden. Otro factor influyente fue la predicación y publicación de Alejandro Bullón, entre los que destacan algunos de sus primeros libros en portugués, como Conocer a Jesús es todo $0^{48}$ y Crisis existencial. ${ }^{49}$ Estas obras contribuyeron significativamente al hecho de que muchas personas que vivían una religión de mero formalismo doctrinal tuvieran un encuentro genuino con Cristo. El nuevo énfasis relacional fue en cierta medida necesario y llegó en un momento oportuno para la iglesia. Pero, como en casi todos los procesos de transición, también en este caso, lo espiritual no logró detenerse en el punto de equilibrio, y terminó pasando del extremo del formalismo doctrinal al otro extremo del existencialismo subjetivo. Aturdidos por la relación mística con Cristo, algunas personas comenzaron a adoptar una postura anti doctrinaria, en la que las doctrinas básicas de la fe adventista llegaron a ser vistas como meros restos de una religión legalista obsoleta.

46 F. C. Webster, "An Argentine Layman Who Knows God's Word, Review and Herald, 2 de enero, 1964, 20.

47 Alberto R. Timm, "Preparo para o batismo: Assunto sério", Revista Adventista, junio 1997, 8-10.

48 Alejandro Bullón, Conocer a Jesús es todo (Florida: Asociación Casa Editora Sudamericana, 1996).

49 Alejandro Bullón, La solución para la crisis existencial (Florida: Asociación Casa Editora Sudamericana, 1995).

https://doi.org/10.17162/recm.v19i1.1591 
La superficialidad actual en el conocimiento de las Escrituras y el descuido de la visión hermenéutica ha contribuido, más que cualquier otra cosa, a destruir la llamada conciencia profética-doctrinal. El estudio objetivo (doctrinal) de la Biblia ha sido reemplazado por una lectura pietista (existencialista), destinada casi exclusivamente a fomentar una relación mística y subjetiva con Cristo. En consecuencia, los sermones de muchas de nuestras iglesias se han vuelto más ligeros, reemplazando en gran medida el contenido doctrinal de la Biblia con las experiencias personales del predicador. ${ }^{50}$

La indiferencia existencialista a las enseñanzas de Cristo también se ha reflejado en la falta de preparación de muchas personas que ingresan a la iglesia hoy. Sin darse cuenta de la diferencia entre el contexto socio-religioso del NT y el complejo mosaico filosófico, cultural y religioso de nuestros días, hay quienes abogan por la teoría de que incluso hoy en día cualquiera puede ser bautizado y aceptado como miembro de la IASD después de escuchar un solo sermón, tal como que predicó Pedro en Pentecostés (Hch 2), o recibir un solo estudio de la Biblia como el que dio Felipe al eunuco (Hch 8:26-40). Incluso, bastaría con escuchar un solo himno como el que cantaron Pablo y Silas en prisión (Hch 16:16-34). Para los partidarios de este nuevo modelo existencialista, cualquiera que profese una relación subjetiva con Cristo puede ser miembro de la iglesia, independientemente de si esa persona acepta o no las enseñanzas doctrinales de Cristo. ${ }^{51}$

\section{Disminución del contenido doctrinal en las series de estudios bíblicos}

Las series de estudios bíblicos que usan cada vez menos la Biblia han dejado a los nuevos miembros vulnerables en su conocimiento de la Palabra. Sin alcanzar un amor genuino por la verdad bíblica y sin comprender la naturaleza profética del movimiento adventista, muchos de estos miembros ven a la IASD como otra denominación evangélica, que difiere vagamente del

51 Comité de Investigación Bíblica de la División Intereuropea de la Iglesia Adventista del Séptimo Día, La teología y práctica del bautismo (Barcelona: Aula7Activa, 2010); Carlos Humberto Cerdá, "Perspectiva hermenéutica de la influencia del Espíritu Santo en la formación de la conciencia religiosa", DavarLogos 11, no. 1 (2012): 81-91. Estos materiales dan una respuesta sólida a la problemática.

https://doi.org/10.17162/recm.v19i1.1591 
resto de las denominaciones que cree en el sábado y la inmortalidad condicional del alma. ${ }^{52}$ No sin razón encontramos muchos ex adventistas en otras denominaciones hoy.

Si el objetivo que se debe lograr es capacitar a la mayor cantidad de personas posible, sin preocuparse por su permanencia en la iglesia, entonces, cuanto más breve y superficial sea la preparación, más fácil será convencer a las personas para que vayan a las aguas bautismales. Pero, por otro lado, si el objetivo es lograr que la mayor cantidad posible de miembros permanezcan en la iglesia y sean misioneros productivos, entonces se les tendrá que enseñar antes del bautismo los fundamentos de la fe. ¿Cómo pueden los nuevos creyentes enseñar a otros la verdad que ellos mismos no han aprendido? (Ro 10:13-15; cf. Jer 48:10).

52 Paulo Cilas da Silva, “Séries de estudos bíblicos da Igreja Adventista do Sétimo Dia no Brasil: Breve história e análise comparativa do seu conteúdo" (Tesis doctoral, Centro Universitário Adventista de São Paulo, 2002). A partir de la década de 1920, se publicaron series de estudios bíblicos publicados en portugués. En el análisis de estas series, se observó que se fundamentan primordialmente en la autoridad de las Sagradas Escrituras, y abordan temas teológicos esenciales como la conversión, la doctrina y la vivencia del estilo de vida cristiano. En el promedio general, los temas más enfatizados son los teórico-doctrinarios. Se puede decir que una buena serie bíblica debe tener aproximadamente el $25 \%$ de temas de conversión, el $50 \%$ de doctrina y del $25 \%$ de estilo de vida, y que hay una media aproximada de 17 textos bíblicos por estudio. Sin embargo, a través de los años se ha comprobado una acentuada disminución en el énfasis doctrinario de los estudios. Una de las evidencias tiene que ver con la cantidad de textos bíblicos por estudio, que viene disminuyendo con el paso de los años, de una media de 26 textos en el primer período (1921-1945), a 13 textos en el quinto (1992-2001). Para da Silva, esta disminución debilita el fortalecimiento del nuevo creyente, quien necesita ser preparado para afrontar doctrinas extrañas de otros credos, filosofías peligrosas del tiempo presente y hasta herejías de disidentes adventistas. $\mathrm{Si}$ se prepara a los conversos solo en una de las áreas mencionadas anteriormente, no solo se está siendo parcial con los interesados, sino que también se está distorsionando la naturaleza global de nuestro mensaje. Si presentamos a Cristo sin doctrinas, se promoverá el pluralismo, una especie de ecumenismo interno que destruye la identidad de cualquier denominación. Si, por otro lado, los estudios propagan doctrinas $\sin$ Cristo, se está difundiendo el legalismo, lo que roba el mensaje de su poder santificador. $\mathrm{Si}$, finalmente, se presenta un estilo de vida que no se deriva de una experiencia espiritual interna, se está estimulando el formalismo, que caracterizó el fariseísmo de los días de Jesús (cf. Mt 23). Así, una preparación adecuada para el bautismo: 1) conduce a la experiencia de la conversión; 2) involucra conocimiento doctrina básico; y 3) promueve la experiencia de un estilo de vida distintivo. Todo esto no representa necesariamente un aumento en el tiempo de preparación, sino un cambio en la visión hermenéutica y metodología que restaure la verdadera identidad profética-adventista. Si pretende que la IASD conserve su identidad denominacional, se debe invertir en una preparación adecuada para las nuevas generaciones que ingresan a sus comunidades.

https://doi.org/10.17162/recm.v19i1.1591 
Sin embargo, el uso esporádico y superficial de las Escrituras no se refleja solo en los sermones y en la preparación de candidatos para el bautismo. Los programas juveniles en muchas de nuestras iglesias han perdido completamente de vista la verdad de las Escrituras. Centrados más en la distracción y el entretenimiento, estos programas ya no ofrecen una oportunidad para que los jóvenes aclaren sus dudas sobre las doctrinas y el estilo de vida que profesamos. ${ }^{53}$ El estudio secuencial de la Biblia, los concursos bíblicos y las competiciones bíblicas hoy son consideradas por muchos como actividades obsoletas y sin sentido. Desafortunadamente, nunca hemos tenido una generación de adventistas tan superficial en su conocimiento bíblico-doctrinal como la generación actual.

La situación actual ha llevado a muchos adventistas a preguntar hasta cuándo continuarán escuchando sermones que prácticamente no conducen a nada y presenciar bautismos de personas que no están comprometidas con la fe que profesan. Timm cree que este problema solo puede revertirse al (1) buscar con insistencia un equilibrio entre la relación con Cristo y el compromiso con Sus doctrinas; (2) volver a estudiar la Biblia para comprender su contenido doctrinal (similar a lo que Miller hizo); (3) predicar los temas fundamentales de la fe adventista; (4) preparar adecuadamente a las personas para el bautismo; (5) memorizar pasajes bíblicos como los Diez Mandamientos, las bienaventuranzas, los tres mensajes angelicales, entre otros; y (6) capacitando a los miembros a través de seminarios para profundizar en el conocimiento de la Biblia. ${ }^{54}$

El interés no debe estar en Cristo sin sus doctrinas, ni en las doctrinas sin Cristo, sino en Cristo con sus doctrinas. En otras palabras, nunca se debe hacer que la relación con Cristo sea un sustituto de las verdades bíblicas, ni debemos exaltar las verdades bíblicas en detrimento de nuestra relación con Él. $.5 \mathrm{Al}$ acercarse rápidamente la mayor crisis entre la verdad y el error de todos los tiempos, el adventismo necesita urgentemente un conocimiento más profundo de "la verdad tal como está en Jesús" (Ef 4:21).

Jose M. Viana argumenta que se debe colocar la misma medida de sal y azúcar, o doctrina y aplicación, de modo que el creyente perciba la singularidad y el amor de la iglesia en partes iguales. Este equilibrio no ha sido fácil de hallar, ya que se transitaron épocas de mucha sal y poca azúcar, poca sal y poca azúcar, o poco de ambas, lo cual da lugar a un fenómeno

53 Véase https://www.youtube.com/watch?v=UL0N_sWIUH0.

54 Timm, "Podemos ainda ser considerados a povo da Biblia?", 14-16.

55 Entrevista con Roy Graf, Universidad Adventista del Plata, Argentina, 11 de abril de 2020 
singular y reciente ya referido: que los ex adventistas se enrolen en cualquier otra iglesia. Viana, además, asegura que el adoctrinamiento intensivo y extenso permite el cambio de hábitos y costumbres más fácilmente que el sistema breve. Por cierto, el pensamiento teológico está relacionado con la práctica. Toda doctrina cristiana importante surgió por razones prácticas y una necesidad real.56

\section{Conclusión}

Los pioneros tenían un énfasis apocalíptico. Este producía un cambio radical de identidad y práctica, a saber, sacrificio, dedicación y coherencia. No sólo creían, sino que vivían en torno a la segunda venida. Cuando el movimiento llega a ser no apocalíptico cae en institucionalismo, autoritarismo, pérdida del foco misionero y descuido doctrinal. Pero estos son simplemente síntomas de la pérdida central de la identidad apocalíptica de los pioneros adventistas. Esto trae como consecuencia, por ejemplo, la creencia en la demora de la venida de Cristo, el rechazo al sectarismo, la mentalidad mundana, la desilusión con el evangelismo, y apreciar la visión apocalíptica como sinónimo de histeria religiosa o exclusivismo. ${ }^{57}$

La IASD ha reconocido el problema y trazado planes para revertir la situación, atendiendo el rescate de ex miembros ${ }^{58}$ y reforzando el discipulado. ${ }^{59}$ Se reconoce que no hay salvación posible sin santidad, sin nueva vida. Más allá de que el diagnóstico sea el correcto, por ahora la situación no se ha revertido. El estancamiento persiste.

Por otra parte, los tiempos institucionales son lentos mientras que las redes avanzan rápido, y una gran cantidad de adventistas, en el contexto de la pandemia, ya no son formados en sus iglesias sino a través del amplio menú que ofrecen los medios virtuales. ¿Tomarán la delantera los predicadores del momento? ¿Reaccionará el liderazgo adventista reformulando su

56 José M. Viana, “O que a Igreja Adventista do Sétimo Dia deve a evangelizacao pública", Parousia 1 (2001), 34.

57 Jiří Moskala y John Peckham, eds., God's Character and the Last Generation (Nampa, ID: Pacific Press, 2018), 133.

58 Edward Heidinger, Guía para secretaría de iglesia (Brasilia: División Sudamericana de la Iglesia Adventista del Séptimo Día, 2017), 100.

59 Unión Argentina de los Adventistas del 7mo Día, “Discipular Unión Argentina”, disponible en https://discipular.adventistas.org.ar/; Erionildes Oliveira Chagas, "El rol de la Escuela Sabática y su relación con el discipulado bíblico cristiano desde la perspectiva de Ellen G. White" (Tesis de maestría, Universidad Peruana Unión, 2019).

https://doi.org/10.17162/recm.v19i1.1591 
enfoque evangelizador desde sus mismas raíces hermenéuticas? Tarea titánica la que se tiene por delante. ${ }^{60}$ ¿Pasará a ser una organización que procura solamente la salud y bienestar de las personas? ${ }^{61}$ El futuro del adventismo depende, en gran medida, de las respuestas a estas preguntas.

60 Fernando Canale, “De la visión al sistema: Terminando la tarea de la teología adventista bíblica y sistemática - Parte II", Theologika 30, no. 1 (2015), 127.

61 Robin Theobald, "From Rural Populism to Practical Christianity: The Modernization of the Seventh-Day Adventist Movement", Archives de sciences sociales des religions 60, no. 1 (1985): 127.

https://doi.org/10.17162/recm.v19i1.1591 